\title{
La rehabilitación urbana sostenible en centros históricos: los casos de León (España) y Puebla (México)
}

\section{Sustainable urban rehabilitation in historic centers: León (Spain) and Puebla (México)}

\author{
María Jesús González González $z^{1}$ y Norma Leticia Ramírez Rosete ${ }^{2}$
}

\section{INTRODUCCIÓN}

La evolución de las ciudades se ha producido paralelamente a los acontecimientos históricos. Cada sector asociado a una época tiene unas características particulares que lo identifican. En las ciudades europeas se encuentran, de manera generalizada, estas características, puesto que las grandes etapas de la evolución urbanística han sido similares en todos los países del Viejo Continente. Sin embargo, también observamos esta evolución en las ciudades mexicanas (Acevedo Salomao, 2002).

Esta herencia urbana ha dado lugar a ciudades en las que la sostenibilidad es un gran reto. La importancia de las ciudades en términos de población, de actividades económicas y productivas, y de relaciones humanas determinantes para la cohesión social son elementos que ilustran su protagonismo en dicho

\footnotetext{
${ }^{1}$ Departamento de Geografía y Geología. Universidad de León (mjgong@unileon.es).

${ }^{2}$ Facultad de Arquitectura de la Benemérita Universidad Autónoma de Puebla (BUAP). (normar25@hotmail.com).
} 
escenario. Las ciudades y sus patrones de crecimiento -claramente insostenibles- son los responsables de la degradación ambiental del planeta a escala global. Su huella ecológica cada vez es más profunda y extensa. Los impactos ambientales derivados del consumo de recursos y de la generación de residuos se extienden por todo el planeta. La globalización económica contribuye a la expansión de otros muchos efectos negativos (Córdoba Montufar, 2008).

El objetivo de este trabajo es analizar los cambios que han tenido lugar en los cascos históricos de las ciudades de León y Puebla. También, se pretende estudiar las estrategias de rehabilitación, revitalización e intervención en estos barrios. Por otro lado, se intenta identificar las repercusiones urbanas, económicas y sociales de estos proyectos de rehabilitación urbana (Ramos Hidalgo, 2005).

Se propone la definición de una Estrategia de Integración y Rehabilitación Urbana Sostenible (EIRUS), basada en la propuesta de una metodología integrada que analiza la fisonomía, morfología e imagen urbana, tipología urbanoarquitectónica y perfiles urbanos (Arvizu García, 1990). Se enfatizan sus valores e identidad, que se manifiestan a través de sus hábitos, tradiciones y costumbres. Esta estrategia va encaminada a la revalorización social de los cascos históricos de ambas ciudades a través de un desarrollo urbano sostenible que garantice una mayor integración social. La finalidad es elevar la calidad de vida de sus habitantes (Boira i Maiques, 1995).

\section{Contextualización}

Conviene diferenciar, conceptualmente, el centro histórico del centro urbano, ya que no son equivalentes, pero presentan una relación, que podría ser la clave para explicar muchos de sus problemas (García Espinosa, 2005).

El centro urbano se define, básicamente, por el número, densidad y calidad de funciones de todo tipo que acoge, especialmente aquellas relacionadas con el sector terciario y cuaternario.

La centralidad atribuida deriva de sus funciones y no de su localización relativa; también, de la accesibilidad y ésta es directamente dependiente del sistema de transportes y de las redes de comunicación, que no tienen por qué responder a un modelo territorial radio concéntrico.

Por lo tanto, el centro urbano no puede ser considerado como una entidad espacial definitiva, sino como una reunión de funciones y actividades que desempeñan un papel de intercomunicación entre los diversos elementos de la estructura urbana (Castells y Borja, 1997). Se trata, por tanto, de una noción netamente sociológica que expresa antes un contenido que una forma. 
Cuando se hace referencia al centro histórico, hablamos de la ciudad antigua, aquella que hoy es solo una parte de la estructura urbana y que va unida, singularmente, a la memoria colectiva de los ciudadanos, a través de su patrimonio edificado, de la configuración de su plano y de sus monumentos.

Una gran parte de las investigaciones sobre centros históricos coincide en señalar que la condensación histórica hace de estos sectores piezas fundamentales del paisaje urbano. Ello provoca que su significación social desborde, con mucho, el papel que le correspondería si atendiésemos a su tamaño, entidad demográfica o económica (Audefroy, 2000).

La problemática de degradación física y social es una constante en algunos de los espacios de estas ciudades y corresponde a un fenómeno generalizado de abandono de los centros históricos, debido a diversos factores entre los que se encuentran el crecimiento y transformación urbana acelerada de las ciudades, tanto en España como en México.

\section{Metodología}

La metodología seguida es la de Estrategias de Integración y Rehabilitación Urbana Sostenible en los centros históricos de León y Puebla. La rehabilitación urbana sostenible es un modelo de integración armónica para mejorar el aspecto urbano que presentan los centros históricos de las dos ciudades. Este modelo puede ser considerado como una guía de intervención y rehabilitación urbana, que complemente los estudios de barrios históricos de cualquier ciudad.

Se pretende demostrar que, a través de la aplicación de esta metodología, se puede revertir ese proceso de abandono y degradación produciendo una revitalización social, urbana, ambiental y económica de los barrios. Uno de sus resultados es el desarrollo sostenible de éstos, entendiendo la sostenibilidad como el esfuerzo sistemático permanente y continuo que realizan los individuos, los actores sociales, las instituciones gubernamentales y no gubernamentales, y las personalidades, para liberar los obstáculos que retrotraen y deterioran estos espacios (Collin Delavaud, 2008).

Las bases de ese proceso son conjugar la rehabilitación arquitectónica y urbana, la revalorización de las actividades que en ellos se realizan y las operaciones destinadas a dinamizar la vida económica y social de un sector decadente de la ciudad.

Los factores que este modelo reúne son la intervención y rehabilitación urbana mediante la renovación de viviendas, tercerización, peatonalización y recuperación de espacios públicos. 
Estos elementos se integran promoviendo una sostenibilidad urbana que repercute en el aumento de la calidad de vida y de la cohesión social de sus comunidades.

Las fuentes de información para realizar esta investigación son un exhaustivo trabajo de campo de las dos ciudades (que se ha desarrollado en el marco de cooperación firmado entre las dos universidades) y la obtención de información de las respectivas instituciones oficiales, como los planes de ordenación y los proyectos de rehabilitación urbana.

\section{RASGOS Y CRITERIOS DE CARACTERIZACIÓN DE LOS CENTROS HISTÓRICOS}

Los cascos históricos representan una estructura de espacios diversificados y siguen conservando una cierta heterogeneidad con los usos del suelo y sus ocupantes. Esto da lugar a un flujo de usuarios de todo tipo que, unido a la variedad de grupos sociales residentes, conforman un paisaje rico en el cual la experiencia cosmopolita, típicamente urbana, encuentra allí su acomodo natural (Lalana Soto, 2011).

Sin embargo, desde el punto de vista funcional, pueden darse distintas situaciones de acuerdo a la clasificación propuesta por Troitiño (2003):

a) Centros históricos que han dejado de ser el centro urbano a nivel económico-funcional, pero que conservan la centralidad simbólica y cultural (Cuenca, Cáceres, Zaragoza, Barcelona, Oviedo).

b) Centros históricos donde lo histórico y lo funcional mantienen diversos niveles de imbricación conservando elementos de centralidad (Madrid, Valladolid, Segovia, León, Guadalajara, Salamanca, Ávila y Puebla (México).

c) Centros históricos que continúan siendo el centro funcional de la ciudad actual (Toledo, Santiago, Teruel, Plasencia).

Los rasgos anteriores caracterizan la mayor parte de los centros históricos, aunque existen unos comunes que los han marcado fuertemente: los problemas y transformaciones de orden social, funcional y morfológico, que arrastran desde mediados del siglo xx (pérdida de población, tercerización del espacio, daño ambiental, formación de áreas con problemas).

Si tenemos en cuenta el criterio deterioro podemos establecer la tipología de sectores internos del centro histórico, ya que el espacio no es homogéneo. Así, Levy (1987) diferencia entre:

a) Sectores en equilibrio social y físico, que conservan protagonismo en la ciudad actual por su carácter multifuncional. 
b) Sectores en proceso de ajuste con espacios que, gracias a determinadas actuaciones, han roto el ciclo de degradación.

c) Sectores en expectativa, que conservan ciertos elementos de centralidad histórica, patrimonio monumental y una situación social, la cual permite la puesta en marcha de procesos de recuperación.

d) Sectores en crisis en los que los procesos de deterioro físico y degradación social y funcional están muy avanzados.

La mayoría de los problemas que presentan estos centros históricos están relacionados entre sí, con el propio desarrollo de la ciudad y con los distintos factores sociales, políticos, económicos, tecnológicos y culturales que lo impulsan. La pérdida de población es, sin duda, una de las características más acusadas de estos barrios. Ello va acompañado de un progresivo envejecimiento de la población residente (en su mayor parte, pensionistas, jubilados, viudos) y por tanto, de escasa renta (Tomé Fernández, 2007).

El mal estado de conservación de los edificios, la inadecuación de su tejido urbano para el uso automovilístico, la ausencia de dotaciones básicas (escuelas, ambulatorios, comercios, zonas verdes) y la falta de condiciones higiénicas elementales, así como otros factores, tales como las tecnologías de la comunicación y la motorización de la sociedad, explican que la población, sobre todo los jóvenes, prefiera trasladarse a las viviendas modernas (Troitiño Vinuesa, 1992).

Los centros históricos se vieron afectados por los llamados procesos de estigmatización socioespacial. Se trata de una versión del teorema de Thomas (Merton, 1995) sobre la definición de la situación: si ésta se define como real, es real en sus consecuencias. La imagen social que se ha construido sobre ellos, les dota de una identidad marginal, problemática y delictiva.

\section{Los casos de León y Puebla}

En la actualidad, León y Puebla tienen zonas deterioradas y otras atractivas y recuperadas, donde se han llevado a cabo operaciones de renovación, contribuyendo a la expulsión de la población tradicional. Además, existe un proceso de tercerización del uso del suelo y una tendencia a la mono funcionalidad en algunos sectores del centro histórico.

Así, en León se han abandonado muchas de las actividades comerciales tradicionales y ha tenido lugar una ocupación selectiva de los locales, especializada en la hostelería (donde proliferan los bares, restaurantes y pubs que generan mucho ruido, perjudicando a los habitantes). 
Esta misma situación ha acontecido, durante la primera década del siglo XXI, en el barrio de los Sapos, en el oriente del centro histórico de Puebla. Ha provocado una pérdida de vitalidad funcional y la progresiva desaparición del uso residencial y de los servicios comunitarios (Terán Bonilla, 2008).

Este proceso ha dado lugar a una gentrificación que, evidentemente, será catastrófica para la cohesión social, valores e identidad. Estos rasgos aún quedan en los barrios históricos como elementos de resistencia cultural que han perdurado a lo largo del tiempo (Coulomb, 2009, 2010).

El abandono de la función residencial tradicional de los barrios históricos deja espacio libre para la actuación y expresión de la delincuencia juvenil, la drogadicción, la prostitución y las formas espontáneas de los crímenes, causando problemas de inseguridad y hacinamiento, cuya expresión máxima se establece en lo que conocemos como vecindades (viviendas multifamiliares de casas pequeñas ubicadas a los lados de un pasillo o patio central). (Ramírez, 2014).

Se debe tener en cuenta que las ciudades son unidades vivas en continuo uso y, como tales, están sujetas a un proceso de transformación; este fenómeno hace que ofrezcan una imagen urbana distinta en cada época (Terán Bonilla, 2010).

La pérdida poblacional en los cascos históricos fue cuantiosa, llegando a superar en León el 47\% desde la década de los sesenta hasta 1995 (González, 2005). A partir de esta fecha se produce una recuperación demográfica, debido a la rehabilitación y renovación de algunas áreas con viviendas nuevas.

En lo que respecta a Puebla, durante el periodo 1982-2010, su centro histórico perdió aproximadamente el $80 \%$ de su población original, lo que representa una disminución promedio de 8.625 residentes por año (cuadro 1).

CuAdro 1

POBLACIÓN DE LOS CENTROS HISTÓRICOS

( $\mathrm{n}^{\mathrm{o}}$ de habitantes)

\begin{tabular}{lccccccc}
\hline & 1960 & 1981 & 1082 & 1994 & 1996 & 2010 & 2014 \\
\hline León & 10.841 & 6.382 & & 5.511 & & 7.555
\end{tabular}

Puebla

$\begin{array}{llll}282.598 & 81.706 & 41.091 & 41.500\end{array}$

Fuentes: Ayuntamiento de León e Instituto Municipal de Planeación de Puebla. 
Por lo tanto, las distintas intervenciones, que se han llevado a cabo en estos barrios de las dos ciudades, ponen de manifiesto que este proceso de abandono se ha detenido e, incluso, comienza a revertirse.

Los comercios antes existentes en estas áreas, en los que predominaban los talleres de artesanos y oficios tradicionales (plateros, joyeros, zapateros, ferreteros, tiendas de telas, ultramarinos) han ido desapareciendo progresivamente o se han transformado en actividades hosteleras ante la imposibilidad de competir con el auge de los grandes comercios situados en las zonas nuevas de ambas ciudades.

La tercerización de la economía y el cambio gradual en el uso del suelo, que se presenta en los dos centros históricos, ha dado lugar a que predomine el uso mixto (habitacional/servicios y habitacional/comercio). La mezcla en los usos del suelo ha introducido cambios importantes en la composición orgánica de la población de los barrios históricos, provocando un trasvase poblacional. La población tradicional del barrio se desplaza hacia la periferia y los nuevos residentes ahora son de clase social baja, predominantemente. El fenómeno de desplazamiento pone de manifiesto una serie de consecuencias, no solo en las prácticas socioculturales del barrio, sino también en los problemas del deterioro físico, espacial y ambiental, asociados al abandono de los servicios públicos del barrio (Ramírez, 2014). Esta situación se presenta, de manera más acentuada a lo largo del siglo xx, en León, Puebla y en otros centros españoles, mejicanos y en el mundo (García Téllez, 2006).

En relación a la vivienda, por tratarse de un tejido conformado en la Edad Media y poco modificado desde entonces, el entramado se adecuaba a las necesidades de la población de aquella época pero no de la actual. Además, la práctica inexistencia de plazas de aparcamiento, la dificultad para circular por las calles con el vehículo o aparcarlo a la intemperie, la contaminación acústica y el difícil equilibrio entre el tránsito peatonal y la circulación del tráfico, fomentaron el abandono de estos espacios.

En los años posteriores, la sensación de inseguridad estaba latente y la estigmatización social en aumento. Los habitantes de las dos ciudades transmitieron este malestar a las autoridades locales, reclamando una rehabilitación y mejora de sus barrios. Pero las autoridades no supieron abordar esta problemática, al no existir unos marcos legales para la resolución de dichos conflictos que guiaran a las ciudades en su configuración.

Estos instrumentos, en los que se establecen las pautas de actuación, se han concertado «a posteriori», principalmente en los nuevos planes de ordenación urbana (PGOU de León de 2004 y PMDUS de Puebla de 2007) y en los programas de rehabilitación de viviendas antiguas y renovación de los 
centros históricos. En León, se han promovido el RE-Urban Móvil de 19972000 y el plan Área de Rehabilitación Integrada (ARI), desde 2003. En Puebla, el Programa Parcial de Desarrollo Urbano y Conservación del Centro Histórico de 1995 y el Plan para la Recuperación de la Zona de Monumentos de 1999.

A partir de este momento, se pone el énfasis en la construcción del modelo integrado por una serie de variables, entre las que destaca la participación social como mecanismo a través del cual se logra concienciar y sensibilizar a la población para que se involucre en la protección y conservación del patrimonio histórico urbano y arquitectónico.

Otra de las variables que intervienen en el modelo de rehabilitación urbana son las estrategias de intervención urbano-arquitectónica en los barrios (Terán Bonilla, 2008).

\section{LA SOSTENIBILIDAD, REHABILITACIÓN Y RENOVACIÓN DE LOS CASCOS HISTÓRICOS DE LEÓN Y PUEBLA}

El paisaje cultural heredado es una realidad urbana dinámica donde los problemas de reorganización interna (reforma, renovación, protección o recuperación) han estado siempre presentes. Por ello, no existe una vía única de intervención en los centros históricos, primando, en unos casos, planteamientos conservacionistas y, en otros, posturas enmarcadas en estrategias de recuperación de naturaleza más integral. Esta última es el objetivo prioritario del modelo de intervención en las dos ciudades

Siempre que en la Historia se producen cambios socioeconómicos de gran calado (es el caso de la revolución de las nuevas tecnologías de la informática y de la telemática, del turismo de masas o de la globalización de las pautas de consumo) hay que replantearse, en nuevos términos, la cuestión de la funcionalidad de los centros históricos (Milán Ávila, 2000). En la vida de una ciudad, en cuanto realidad urbana viva y dinámica, las políticas de protección y recuperación, para ser eficaces, tienen que dotarse de instrumentos capaces de regular la tensión existente entre unas realidades físicas estáticas y unas realidades socioeconómicas cambiantes (García-Hípola y Beltrán Rodríguez, 2011).

Así, los factores de rehabilitación son:

- Salvaguardar el carácter particular y la identidad cultural de los centros y sus barrios. 
- Formular estrategias para elevar la calidad de vida de su población residente, dignificación y recuperación de la vivienda en torno a actividades lúdicas, comercio, turismo, etc.

- Revitalizar los espacios públicos y mejorar las condiciones de movilidad y accesibilidad (MIC, 2013).

Es más sostenible la rehabilitación del patrimonio ya existente y consolidado que la expansión periurbana sobre espacios aún sin conformar (Blanc, 2003). Antes de expandirse es necesario afrontar las problemáticas existentes en el interior de las áreas consolidadas, para lograr el funcionamiento adecuado y equilibrado del sistema urbano, requisito de la sostenibilidad. Para ello, es preciso retener a la población residente y atraer a nuevos vecinos.

Por otra parte, la rehabilitación de los edificios históricos tiene como plus de sostenibilidad la aplicación de las recientes medidas sobre ahorro energético y de agua -ecoeficiencia de los edificios e instalaciones-, la accesibilidad y poder paliar las deficiencias constructivas que algunos presentan.

Se propicia la cohesión social, la calidad arquitectónica y el uso de materiales no contaminantes (Valverde Díaz de León, 2005). Otro punto a favor es la posibilidad de adaptación de las tipologías residenciales a los nuevos patrones familiares y demográficos. Además, ello va asociado a la redinamización económica de estos espacios, porque favorece la instalación de negocios o la atracción de empresas, que repercutirán positivamente en el empleo local (Milán Ávila, 2000).

Las cambiantes condiciones socioeconómicas y culturales de la sociedad producen modificaciones en las tendencias de la evolución de las ciudades con el paso del tiempo. Por ello, la situación de estos barrios antiguos con respecto a épocas anteriores se revirtió a inicios del siglo XxI (Terán Bonilla, 2010). Desde entonces, se ha iniciado un periodo de dignificación urbanística, revalorización estética, revitalización económica y recuperación de estas áreas con funciones residenciales, económicas y lúdicas (Martínez Vicente, 2014).

En el cuadro 2 se plantean las características funcionales, formales, sociales y ambientales de la revitalización de los centros históricos, con el objeto de proponer acciones para mantenerlos como espacios vivos. Se apoyan en la rehabilitación arquitectónica y urbana, el equipamiento y servicios urbanos, la imagen urbana, la restauración del patrimonio edificado y, en algunos casos, si es necesario, la inserción de nuevas edificaciones mediante arquitectura de integración. 


\section{CUADRO 2}

\section{CARACTERÍSTICAS DE LAS ESTRATEGIAS DE REHABILITACIÓN E INTERVENCIÓN URBANA SOSTENIBLE EN LEÓN Y PUEBLA}

\begin{tabular}{|c|c|}
\hline $\begin{array}{l}\text { CARACTERÍ́STICAS } \\
\text { FunCIONALES }\end{array}$ & $\begin{array}{l}\text { - Utilización de las técnicas de la rehabilitación urbano-arquitectónica de los espacios en } \\
\text { deterioro. } \\
\text { - Mejorar y renovar la infraestructura existente (viales, agua potable, drenaje y alcantari- } \\
\text { llado, telefonía y energía eléctrica). } \\
\text { - Mejora del equipamiento urbano. } \\
\text { - Adaptación de los espacios a las actividades recurrentes del lugar } \\
\text { - Uso de la restauración y renovación en inmuebles } \\
\text { - Reutilización del patrimonio cultural de los siglos anteriores } \\
\text { - Revitalización a través del impulso de la vocación propia de la zona } \\
\text { - Optimizar las vías de comunicación existentes } \\
\text { - Peatonalización de las calles y recuperación de plazas y espacios públicos } \\
\text { - Reordenar las rutas de transporte urbano } \\
\text { - Intervención integral y no concentrada en un solo punto de la zona central } \\
\text { - Rehabilitación y conservación del uso residencial }\end{array}$ \\
\hline $\begin{array}{c}\text { CARACTERÍ́STICAS } \\
\text { FORMALES }\end{array}$ & $\begin{array}{l}\text { - Recuperación de la dinámica de la zona central y su atractivo urbano } \\
\text { - Catalogación de los edificios de valor histórico existente para conservarlos y reutilizarlos } \\
\text { - Mantener la continuidad del trazado urbano original. } \\
\text { - Restaurar los inmuebles característicos de la arquitectura típica } \\
\text { - La inserción de la arquitectura moderna respetará el lenguaje morfológico característico } \\
\text { - Revalorización del patrimonio edificado en siglos anteriores } \\
\text { - Reconstrucción de la imagen típica de la zona. } \\
\text { - Reactivación de la obra pública para mejorar y renovar infraestructuras y equipamien- } \\
\text { tos existentes }\end{array}$ \\
\hline $\begin{array}{c}\text { CARACTERÍSTICAS } \\
\text { SOCIALES }\end{array}$ & $\begin{array}{l}\text { - Dinamizar la vida económica y social de los sectores en decadencia } \\
\text { - Recuperación de espacios públicos (plazas, parques) que son lugares de encuentro social } \\
\text { - Implementar una serie de incentivos fiscales, económicos o de uso del suelo para im- } \\
\text { pulsar las intervenciones en la zona } \\
\text { - Recuperación del liderazgo económico característico del lugar } \\
\text { - Evitar la invasión y privatización del espacio público } \\
\text { - Fomentar la permanencia de la sociedad residente y que sus actividades socioeconómi- } \\
\text { cas no propicien el fenómeno de deterioro } \\
\text { - Turismo urbano patrimonial } \\
\text { - Atracción de la población joven } \\
\text { - Incremento de la inversión inmobiliaria en la zona } \\
\text { - Rescate de la identidad cultural que permita el arraigo de sus habitantes con su entorno }\end{array}$ \\
\hline CARACTERÍSTICAS & $\begin{array}{l}\text { - Revalorizar las áreas urbanas del lugar } \\
\text { - Potenciar y mejorar el uso de los espacios con presencia de áreas verdes con vegetación } \\
\text { propia del lugar } \\
\text { - Mejorar las condiciones físicas mediante el saneamiento urbano } \\
\text { - Mejorar la recogida de basuras. Recogida neumática (León) }\end{array}$ \\
\hline
\end{tabular}

Fuente: Elaboración propia a partir de García Centurión (2011).

Estudios Geográficos, Vol. LXXVI, 279, pp. 531-555, julio-diciembre 2015

ISSN: 0014-1496, eISSN: 1988-8546, doi: 10.3989/estgeogr.201519 


\section{León}

Para luchar contra los fenómenos de abandono y degradación de los centros históricos, desde finales del siglo xx, la Unión Europea ha puesto en marcha programas de financiación para la rehabilitación del patrimonio histórico mediante los Fondos Estructurales, gestionados, en gran parte, por las autoridades nacionales y regionales. Mayoritariamente, se conceden subvenciones a fondo perdido para la renovación del hábitat y la fijación de población, aunque también se ofrecen beneficios fiscales y préstamos con condiciones ventajosas. A nivel estatal, se conceden ayudas para la remodelación urbana en España.

La preocupación por la recuperación del patrimonio histórico e inmobiliario y la repoblación de espacios degradados surgió en España a finales de la década de los 80, al mismo tiempo que llegaron las primeras ayudas europeas. Esta inquietud se refleja, también, en las normativas nacionales y regionales en materia de ordenación territorial (cuadro 3).

En España, la Ley de Patrimonio (Ley 16/1985, de 25 de junio, del Patrimonio Histórico Español) obligaba a formular un plan especial de protección o cualquier otro instrumento de planeamiento para estas áreas singulares y a la aplicación de las normativas de patrimonio histórico, que se propuso como herramienta para salvaguardar los bienes culturales (Manero, 2009).

A pesar de haber sido declarada la ciudad antigua de León conjunto histórico artístico en 1962, constituía un espacio muy degradado. Con la aprobación del Plan Especial en 1995 y del Proyecto Piloto Urbano (1997-2000), se apuesta por la regeneración urbana del centro histórico. Su ámbito de aplicación incluye el interior amurallado, tanto romano como medieval, además de algunos terrenos aledaños que constituyen los arrabales históricos. Se ha actuado y se está actuando de una forma profunda en el tejido residencial y en las dotaciones e infraestructuras del barrio para favorecer un desarrollo equilibrado.

A partir de 1995 se inicia una catalogación de edificios para recuperar y rehabilitar: edificio de Gaudí, palacio de los Guzmanes, la casa de las Carnicerías, palacio de D. Gutierre, palacio del Conde Luna y varios edificios singulares, como la Casona o antiguo Correos. También comienza la recuperación de espacios públicos en torno a la Catedral, San Isidoro y Arco de la Cárcel. Además se peatonalizan varias plazas y calles y se implanta una recogida neumática de residuos sólidos.

En la nueva Ley del Suelo (Real Decreto Legislativo 2/2008, de 20 de junio, por el que se aprueba el texto refundido de la Ley del Suelo) y en la Ley de Economía Sostenible (Ley 2/2011, de 4 de marzo, de Economía Sostenible) se abordan, también, estos aspectos. Actualmente, las competencias en materia 
de ordenación urbana y planes especiales están transferidas a las comunidades autónomas y, más en concreto, a los ayuntamientos. En el Reglamento de Urbanismo de Castilla y León (Decreto 22/2004, de 29 de enero, por el que se aprueba el Reglamento de Urbanismo de Castilla y León) se establece, como una de las prioridades, la protección del patrimonio cultural y la conservación de los espacios singulares. Esta sigue siendo la tónica en la Ley de Regeneración Urbana de Castilla y León (Ley 7/2014, de 12 de septiembre, de Medidas sobre Rehabilitación, Regeneración y Renovación Urbana y sobre Sostenibilidad, Coordinación y Simplificación en Materia de Urbanismo).

Las figuras y normativas locales son más frecuentes y, entre ellas, destacan los planes parciales, los planes especiales y los estudios de detalle, en los que se abordan las necesidades de cada entidad territorial (Álvarez Mora, 2013).

CuAdro 3

LEGISLACIÓN Y NORMATIVAS FUNDAMENTALES DE PLANIFICACIÓN TERRITORIAL Y REHABILITACIÓN SOSTENIBLE INTEGRADA

\begin{tabular}{l|l}
\hline \multicolumn{1}{c|}{ Legislación en España /León } & \multicolumn{1}{c}{ Legislación en México/Puebla } \\
\hline Conjunto Histórico Artístico (1962) & $\begin{array}{l}\text { Ley Federal sobre monumentos y zonas arqueológi- } \\
\text { cas, artísticas e históricas (1972) } \\
\text { Plan para la Revitalización del Casco Histórico de la } \\
\text { Ciudad de Puebla (1982) } \\
\text { Ley de Patrimonio de 1985 }\end{array}$ \\
$\begin{array}{l}\text { Plan Especial de Ordenación del Centro Histórico de Puebla como Pa- } \\
\text { (1995) }\end{array}$ & $\begin{array}{l}\text { Progonio Cultural de la Humanidad, UNESCO (1987) } \\
\text { Histórico de la Ciudad de Puebla (1990) }\end{array}$ \\
Proyecto Piloto Urbano (1997-2002) & $\begin{array}{l}\text { Programa Parcial de Desarrollo Urbano y Conservación } \\
\text { del Centro Histórico de la Ciudad de Puebla (1994) } \\
\text { Plan para la Recuperación de la Zona de Monumen- } \\
\text { tos de la Ciudad de Puebla ( 1999-2000) }\end{array}$ \\
Urban /Re-Urban Móvil (1997-2003) & $\begin{array}{l}\text { Programa Municipal de Desarrollo Urbano Sosteni- } \\
\text { ble, PMDUS (2007) }\end{array}$ \\
(2003-2013) Áreas de Rehabilitación Integrada, ARI & $\begin{array}{l}\text { Código Reglamentario del Municipio (2008) } \\
\text { Plan de regeneración urbana DUIS }\end{array}$ \\
Ley del Suelo (2008) & $\begin{array}{l}\text { pio de Puebla (2011) } \\
\text { Programa sectorial del Centro Histórico (2013) }\end{array}$ \\
\hline Ley de Economía Sostenible (2011)
\end{tabular}

Fuente: Elaboración propia. 
La estructura urbana consta de los barrios históricos de San Martín -popularmente llamado Barrio Húmedo-, dedicado tradicionalmente al comercio y oficios artesanos y, en la actualidad, a la restauración y bares, y Santa Marina (barrio nobiliario y monumental), que se ha terciarizado. En él se encuentran varios colegios de enseñanza (figura 1 y figura 2 ).

FIGURA 1

PLANO DE LA CIUDAD DE LEÓN

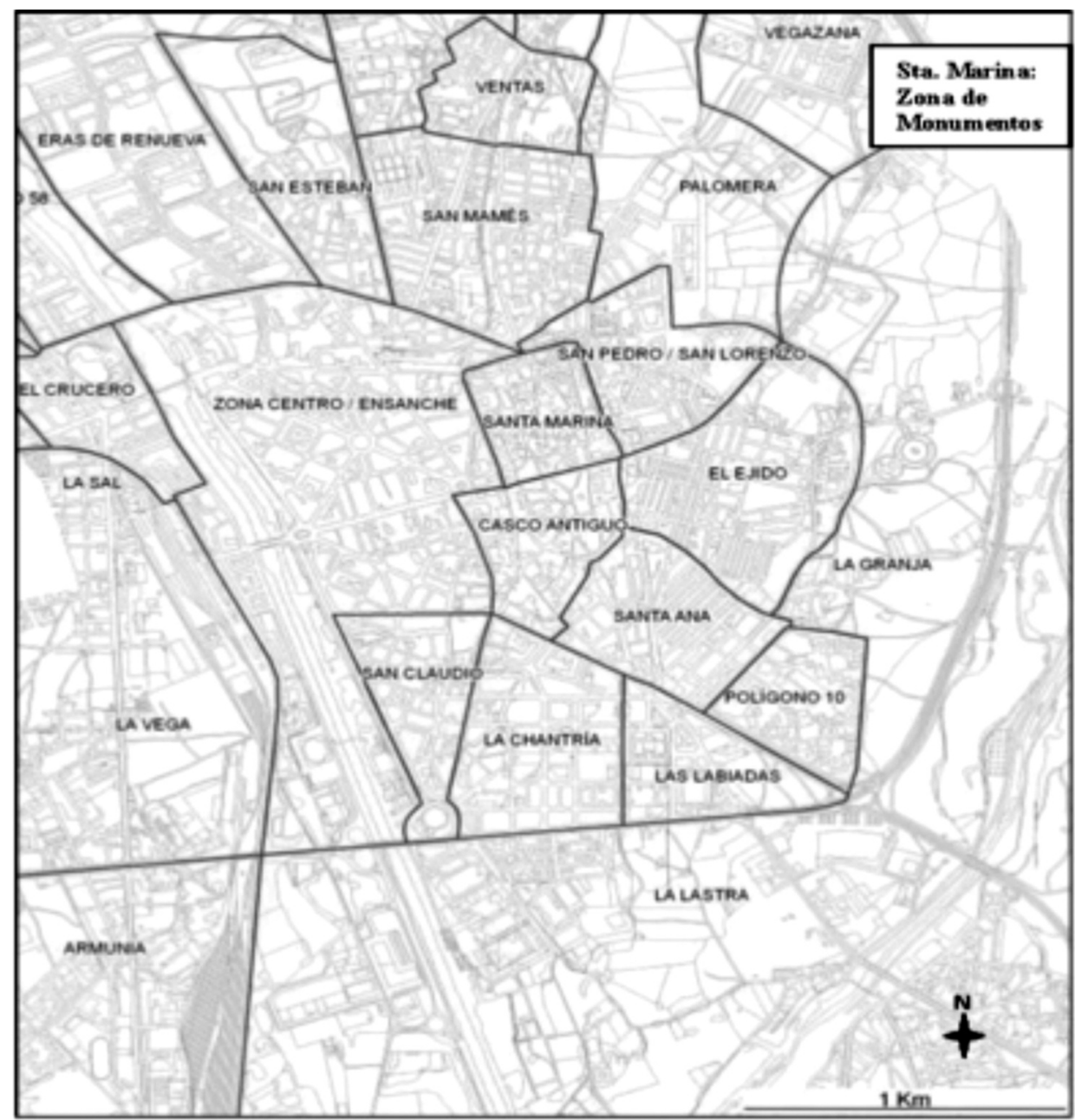

Fuente: Ayuntamiento de León. Elaboración propia 
FIGURA 2

\section{EL CENTRO HISTÓRICO DE LA CIUDAD DE LEÓN}

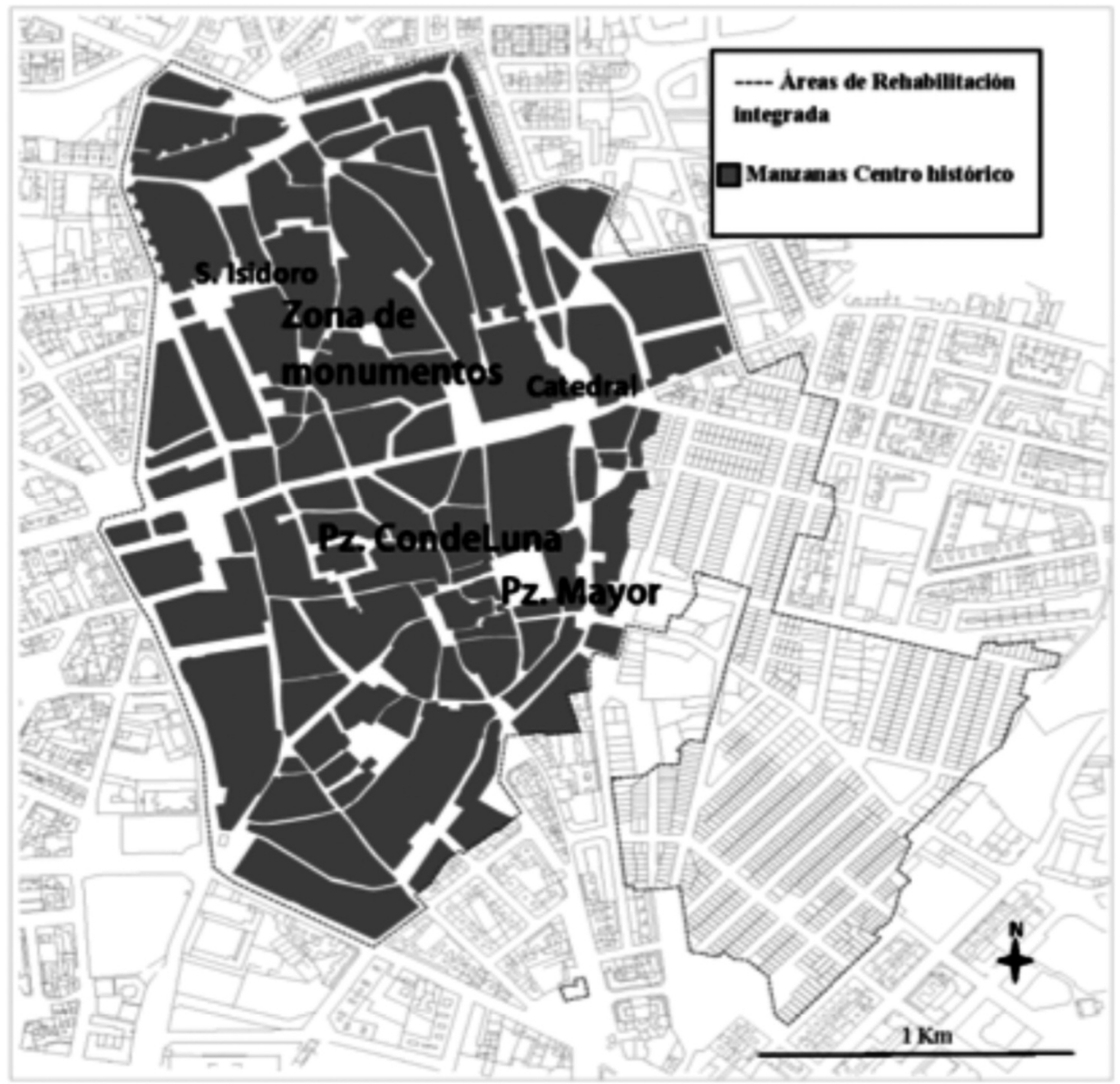

Fuente: Ayuntamiento de León. Elaboración propia.

El trazado de sus calles es medieval: manzanas irregulares, edificios estrechos y profundos con huecos verticales, balcones, miradores, aleros de madera, etc. Hoy en día sigue siendo una importante zona comercial y de ocio de la ciudad, al concentrarse en él los monumentos más representativos y turísticos. Se encuentran gran cantidad de establecimientos de todo tipo, concentrados en las vías principales, entre las que destaca la Calle Ancha, antiguo Decumano del campamento de la Legio VI y, posteriormente, de la Legio VII 
Gemina, que divide a la ciudad antigua. También en el Barrio Húmedo que representa la esencia de la ciudad histórica con sus calles estrechas y empinadas y sus plazas irregulares.

La renovación del casco antiguo leonés, desde finales del siglo xx, es palpable en la recuperación de sus plazas y calles para uso público como, por ejemplo, la peatonalización del Barrio Húmedo (uno de los espacios turísticos más activos de la ciudad) y de la Calle Ancha (conectaba las zonas este y oeste de la ciudad con una gran intensidad de tráfico, que estaba afectando a la catedral).

No obstante, a pesar de la degradación, se han rescatado elementos urbanos y arquitectónicos como el caso del Jardín del Cid y fragmentos de la antigua muralla en el barrio de Santa Marina que, actualmente, han recuperado su función social y ambiental.

Se han rehabilitado, de forma integral, el conjunto del Palacio del Conde Luna y la plaza de Abastos (figura 2), la plaza del Grano, la iglesia del Mercado. Se ha remodelado y creado un aparcamiento subterráneo en la plaza Mayor, en la que se sigue celebrando el mercado de los productos locales los miércoles y los sábados.

Se han recuperado espacios públicos, como las plazas de la Regla, San Isidoro, San Martín, Plaza Mayor (que antes estaba invadida por los automóviles) y, además, se han peatonalizado la mayoría de sus calles, favoreciendo el comercio, el ocio y la socialización de estas áreas.

En esta Rehabilitación Urbana han confluido las acciones públicas y privadas, cuyo objetivo está dirigido a alcanzar la recuperación y reutilización del espacio urbano de una forma integrada. Este modelo de integración pretende ser una guía de intervención urbana que detenga las actuaciones indiscriminadas en los edificios del patrimonio histórico-urbano.

En todas estas actuaciones se ha seguido el modelo extractado en el cuadro 4.

Se han rehabilitado un total de 242 edificios de la ciudad antigua y 3.146 viviendas con el programa ARI. La Junta de Castilla y León declaró ARI la zona de la Ciudad Antigua (figura 2) y parte del Barrio de El Ejido, por Acuerdo de 13 de octubre de 2003. La Consejería de Fomento de la Junta de Castilla y León y el Ayuntamiento de León, han firmado un Convenio de Colaboración para la financiación conjunta de las actuaciones comprendidas en el Área de Rehabilitación Integrada. Se han beneficiado más de 800 viviendas de ayudas públicas. También se han rehabilitado integralmente 130 viviendas por la iniciativa privada, 300 nuevas viviendas en actuaciones de renovación urbana y nuevos equipamientos urbanos (Ayuntamiento de León). 


\section{CUADRO 4}

\section{LEÓN: PLAZA DEL CONDE LUNA, PALACIO Y PLAZA DE ABASTOS}
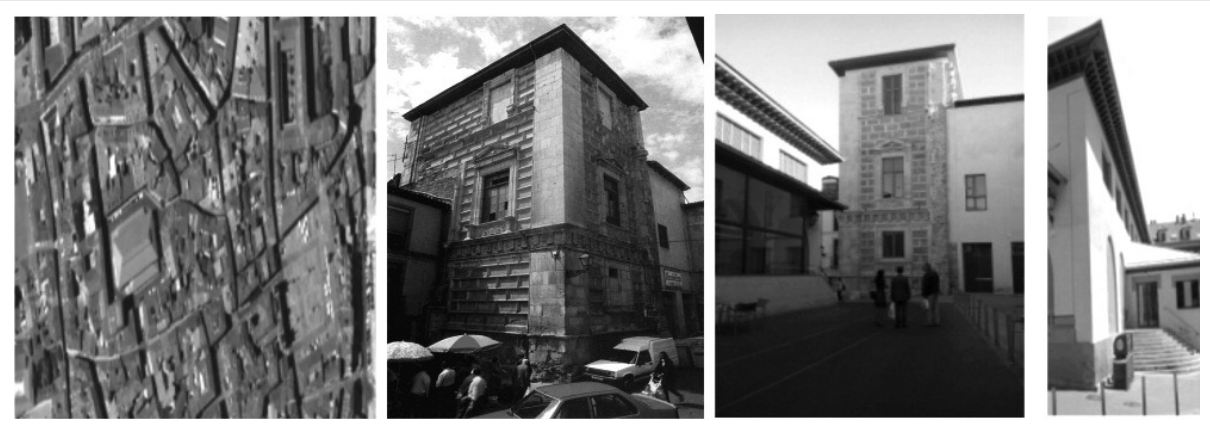

Foto 1.Se trata de mantener parques, plazas y paseos de gran tradición.

Foto 2. Deterioro y degradación de este espacio (invasión del automóvil, torreón era almacén de frutas e invasión de la plaza por comercio ambulante). Declarado en 1931 Monumento Histórico Artístico.

Foto 3. Todo el conjunto se ha remodelado y es un espacio público urbano. Renovación actual de la plaza. Los edificios de la Plaza de Abastos y el Palacio se han transformado en centro educativo, cultural, de exposiciones y conferencias.

Foto 4. Instalación de recogida neumática de residuos sólidos al lado de la Plaza de Abastos.

Características

Descripción

1. Ubicación dentro Se sitúa en la esquina suroeste de la antigua muralla romana. Paso ende la estructura tre la calle Ancha y Barrio Húmedo. Albergue tradicional de múltiples urbana de la ciudad actividades que toman como escenario la vía pública con la Plaza de Abastos. Conjunto de gran riqueza histórica y cultural.

2. Tipo de Equipamiento recreativo, comercial, cultural y ambiental.

equipamiento Del Palacio (siglo XIV) solo se conserva la estructura central de la fachada y un torreón renacentista de tres pisos (alberga la sede de la Universidad de Washington). Durante muchos años ha servido como sede al Tribunal de la Santa Inquisición y del Banco de España, almacén de frutas, un bar e, incluso, una funeraria. Al lado de la Plaza de Abastos se ha instalado la recogida de residuos neumática.

\begin{tabular}{ll}
\hline $\begin{array}{l}\text { 3. Proceso y etapas } \\
\text { del proyecto }\end{array}$ & $\begin{array}{l}\text { El proceso sufrió varias etapas y, en un principio, se pensó en quitar la } \\
\text { Plaza de Abastos. Análisis y evaluación de la zona, definición de mate- } \\
\text { riales y mobiliario, análisis del estado de la infraestructura y recons- } \\
\text { trucción y remodelación. Proyecto URBAN y ARI. }\end{array}$ \\
\hline $\begin{array}{l}\text { 4. Problemas } \\
\text { sociales y urbanos } \\
\text { que deben } \\
\text { solucionarse }\end{array}$ & $\begin{array}{l}\text { Deterioro y degradación urbano-arquitectónico. Invasión del espacio } \\
\text { público por automóviles y, al ser el Palacio almacén de frutas, sufrió } \\
\text { todo el entorno un deterioro ambiental y social. }\end{array}$ \\
\hline
\end{tabular}

Estudios Geográficos, Vol. LXXVI, 279, pp. 531-555, julio-diciembre 2015 ISSN: 0014-1496, eISSN: 1988-8546, doi: 10.3989/estgeogr.201519 
CUADRO 4 (cont)

LEÓN: PLAZA DEL CONDE LUNA, PALACIO Y PLAZA DE ABASTOS

Características

\begin{tabular}{ll}
\hline $\begin{array}{l}\text { 5. Población a la } \\
\text { que se dirige }\end{array}$ & $\begin{array}{l}\text { El proyecto fue concebido para beneficio de los habitantes de la ciudad } \\
\text { en general y del barrio en particular. }\end{array}$ \\
\hline 6. Proyecto & $\begin{array}{l}\text { Busca recuperar la memoria histórica conservando monumentos y es- } \\
\text { pacios urbanos antiguos, rehabilitando los inmuebles de la plaza en } \\
\text { equilibrio con sus habitantes, conservando y desarrollando actividades } \\
\text { productivas para toda la ciudad. }\end{array}$ \\
\hline 7. Impacto que & $\begin{array}{l}\text { Económico: Reactivar la economía donde los habitantes podrán desa- } \\
\text { generó el proyecto } \\
\text { rrollar sus actividades productivas cerca de su residencia y evitar la } \\
\text { emigración de la población de este sector. } \\
\text { Social: Integración ciudadana y revalorización de sitios históricos } \\
\text { Cultural: Recuperar la identidad y el arraigo de usuarios y habitantes } \\
\text { Urbano: Propiciar el desarrollo sostenible y dar seguimiento y aplica- } \\
\text { ción a los programas de desarrollo urbano y al programa parcial de } \\
\text { conservación y mejoramiento del centro histórico. }\end{array}$ \\
&
\end{tabular}

Fuente: Elaboración propia.

\section{Puebla}

La ciudad de Puebla obtiene el nombramiento de Patrimonio Cultural de la Humanidad, por parte de la UNESCO, en 1987, después de haber sido declarada como Zona de Monumentos desde 1977. La ciudad queda enmarcada por una estructura urbana que alberga al centro de la ciudad y los barrios históricos (figura 3). Éstos representan un elemento imprescindible para conocer y comprender la fisonomía urbana actual, producto de la ciudad novohispana de Puebla durante los siglos XVI, XVII y XVIII (Chanfón Olmos, 1997). Por otra parte, su estructura urbana consta de los barrios históricos de San José, San Francisco (El Alto), Santa Anita, Analco, San Miguel, Xanenetla, Xonaca, San Pablo, Los Remedios, La Luz, San Antonio, San Sebastián y Santiago. Sin embargo, es importante aclarar que el barrio de San José, a diferencia de los anteriores, no es un barrio indígena, sino un barrio mestizo que cuenta con un valor histórico y una ubicación estratégica dentro del centro histórico de la ciudad.

Los parámetros y políticas que se ponen en práctica para una recuperación social, urbana y ambiental del centro histórico son: el Plan para la Recuperación de la Zona de Monumentos de la Ciudad de Puebla de 1999 y el Programa Municipal de Desarrollo Urbano Sostenible de Puebla de 2007 
(PMDUS) (cuadro 5). Ambos documentos inciden, directamente, en los usos del suelo, infraestructuras, equipamientos, imagen urbana y en estrategias de rehabilitación urbana sostenible.

No obstante, a pesar de la degradación del barrio de San José y su entorno inmediato, aún se pueden rescatar elementos urbanos y arquitectónicos que conserva desde su fundación; tal es el caso del Jardín Francisco I. Madero, que es un fragmento de la Antigua Alameda.

En este sentido, el Código Reglamentario del Municipio para la protección, mejoramiento y custodia de la Zona de Monumentos de la Ciudad de Puebla (reformado párrafo Primero, p. 29 de agosto de 2008, Artículo 1185) mantiene una corresponsabilidad y compromiso en la conservación y protección y del patrimonio cultural.

En 2011 se inicia la actualización del Programa Parcial de Desarrollo Urbano del Municipio de Puebla, así como las Bases para el Plan de Mejora y Conservación del centro histórico, que tiene como propósito actualizar la estrategia, políticas y normas de desarrollo urbano del municipio.

El Programa Sectorial del centro histórico de 2013 contempla cuatro reservas territoriales para el desarrollo de siete proyectos prioritarios: un hotel de

FIGURA 3

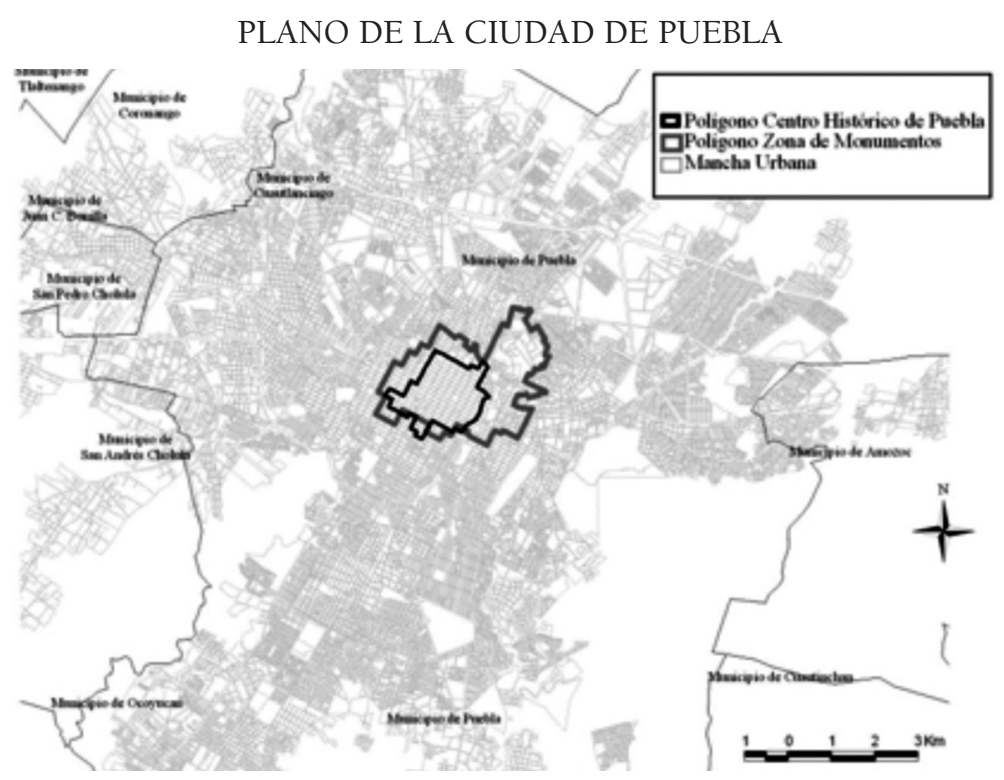

Fuente: INEGI y elaboración propia.

Estudios Geográficos, Vol. LXXVI, 279, pp. 531-555, julio-diciembre 2015

ISSN: 0014-1496, eISSN: 1988-8546, doi: 10.3989/estgeogr.201519 
gran turismo, un Centro de Información y Movilidad Turística, la ciudad creativa del diseño en los barrios de los Remedios y la Acocota, el Paseo del Arte, un hotel de negocios, el Centro del Conocimiento y las Artes y el Centro de Interpretación e Innovación Tecnológica, proyectos cuya estrategia pretende ser un detonante de desarrollo económico.

A pesar de que la recuperación integral del barrio de San José no es prioritaria en los planes y programas de rescate de barrios, en 2008 se aprueba el proyecto "Puesta en Valor de la Parroquia de San José y su Conjunto Histórico". Éste constituye un referente importante para elaborar un modelo de Rehabilitación e Integración Urbano-Arquitectónica, sustentado en su valoración histórica y social (Ramírez Rosete, 2014).

Se pretende implementar un ambicioso Plan de regeneración urbana DUIS (Desarrollo Urbano Integral Sustentable del año 2011) para la Zona de Monumentos y su entorno, que generará un impacto y repercusión social, económica y ambiental (figura 4).

En las actuaciones llevadas a cabo se ha seguido el mismo modelo que ya hemos expuesto y que, a continuación, se resume en el cuadro 5.

FIGURA 4

\section{EL CENTRO HISTÓRICO DE LA CIUDAD DE PUEBLA}

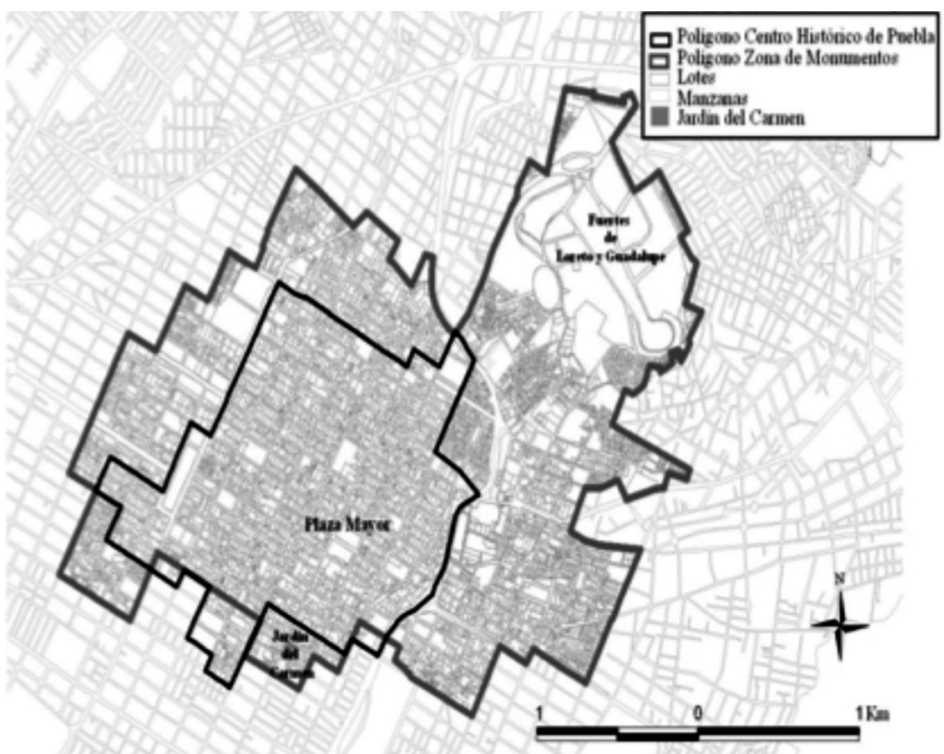

Fuente: INEGI y elaboración propia 
CUADRO 5

PUEBLA: PROYECTO JARDÍN DEL CARMEN
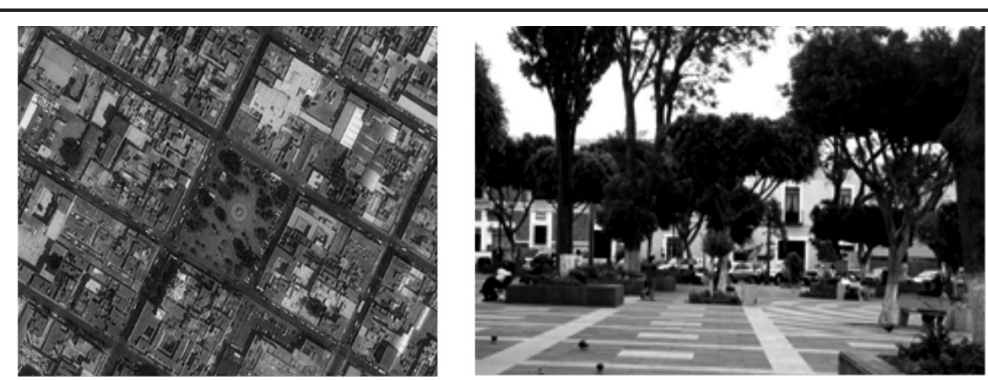

Foto 1. Se pretende la recuperación de espacios públicos para sus habitantes.

Foto 2. Calidad ambiental del sector y rehabilitación de los edificios colindantes .

\begin{tabular}{ll}
\hline \multicolumn{1}{c}{ Características } & \multicolumn{1}{c}{ Descripción } \\
\hline $\begin{array}{l}\text { 1. Ubicación dentro } \\
\text { de la estructura } \\
\text { urbana }\end{array}$ & Se ubica en el sur-oriente del centro histórico. \\
\hline $\begin{array}{l}\text { 2. Tipo de } \\
\text { equipamiento }\end{array}$ & $\begin{array}{l}\text { El proyecto pertenece al equipamiento de recreo y recuperación de es- } \\
\text { pacios públicos para los habitantes del área, de la ciudad y turistas. }\end{array}$ \\
\hline $\begin{array}{l}\text { 3. Proceso y etapas } \\
\text { del proyecto }\end{array}$ & $\begin{array}{l}\text { Análisis y evaluación de la zona del parque del Carmen, definición de } \\
\text { materiales y mobiliario, análisis del estado de la infraestructura, cons- } \\
\text { trucción de jardines y de la fuente. El proyecto se encuentra en el Plan } \\
\text { de Desarrollo 2008-2011, de imagen urbana y mejorar los parques. }\end{array}$ \\
\hline $\begin{array}{l}\text { 4. Problemas sociales } \\
\text { y urbanos que deben } \\
\text { solucionarse }\end{array}$ & $\begin{array}{l}\text { La problemática es el uso inadecuado del espacio abierto por el comer- } \\
\text { cio, además de falta de actividad social en el sentido de recreación e in- } \\
\text { tegración de los habitantes. }\end{array}$ \\
\hline $\begin{array}{l}\text { 5. Población a la } \\
\text { que se dirige }\end{array}$ & $\begin{array}{l}\text { A los habitantes del barrio y turistas. } \\
\text { 6. Proyecto }\end{array}$ \\
$\begin{array}{l}\text { Actualmente, la administración pública ha optado por aplicar proyec- } \\
\text { tos dirigidos a rescatar el patrimonio no solo arquitectónico, sino tam- } \\
\text { bién urbano, del centro histórico. Los parques y jardines son muy } \\
\text { importantes para recuperar el valor ambiental de esta zona. Este par- } \\
\text { que y su parroquia es un punto de referencia para la sociedad poblana. }\end{array}$ \\
$\begin{array}{ll}\text { Económico: Proyecto ambicioso que superó la inversión inicial ade- } \\
\text { meró el proyecto } \\
\text { más de beneficiar el uso comercial del entorno. } \\
\text { Social: Atractivo para la población. Ha contribuido a revertir el despo- } \\
\text { blamiento que está sufriendo el barrio del Carmen. } \\
\text { Cultural: Es un hito que continúa siendo un punto de reunión y con } \\
\text { tradiciones culturales como la festividad del barrio. } \\
\text { Urbano: El diseño urbano buscó mejorar la imagen urbana mediante } \\
\text { nuevo mobiliario, alumbrado público. No mejoró la calidad ambiental } \\
\text { del barrio. }\end{array}$ \\
\hline
\end{tabular}

Fuente: Elaboración propia a partir de Ramírez, 2014.

Estudios Geográficos, Vol. LXXVI, 279, pp. 531-555, julio-diciembre 2015

ISSN: 0014-1496, eISSN: 1988-8546, doi: 10.3989/estgeogr.201519 


\section{CONCLUSIÓN}

El abandono de los cascos antiguos, producido desde mediados de los años 60 en las dos ciudades de estudio, se originó por la obsolescencia, el deterioro y la insalubridad de su parque inmobiliario y por los problemas derivados del envejecimiento de sus residentes, de sus bajos ingresos económicos, de las minorías étnicas (principalmente en Puebla) y la escasa actividad económica. Todo ello conllevó el desperfecto en edificios y calles, lo que produjo la huida de la población residente hacia lugares más agradables para vivir. El empobrecimiento y la marginación de estos espacios han supuesto el abandono de su patrimonio histórico y cultural y ha generado sensación de inseguridad. Para hacer frente a estos problemas, la rehabilitación urbana se presenta como la solución más sostenible y respetuosa con el medio ambiente, para terminar con la obsolescencia urbana y fijar población.

La renovación del centro histórico de León y Puebla ha sido muy importante para asegurar la cohesión, la integración urbana y la calidad de vida de sus habitantes. A partir de la década de los ochenta, la pérdida poblacional del centro de las dos ciudades y el abandono de inmuebles inciden en la creación de un paisaje caótico, confuso e inseguro donde se han insertado edificios con estilos arquitectónicos diversos, afectando a la imagen urbana de este sector.

A raíz del desarrollo de los programas de las áreas de rehabilitación integrada se ha observado en los dos centros históricos:

- La recuperación y preservación del Patrimonio Histórico, Cultural y Urbano heredado.

- Se ha elevado la calidad de vida de residentes, mejorando las condiciones de habitabilidad de sus viviendas.

- Se ha dotado de todo tipo de servicios a estos espacios, demandados por una sociedad desarrollada. Por ejemplo, la recogida neumática de las basuras en León (Barrio Húmedo).

- Se impulsan y desarrollan actividades económicas que posibilitan un desarrollo armónico.

- Se implica a todos los ciudadanos en su conservación y mantenimiento. Así, se han creado asociaciones de vecinos en estos barrios, para canalizar sus reivindicaciones, como la insonorización de locales, particularmente en León.

- Se ha revertido el proceso de abandono de las viviendas, actualmente, por parte de la población. El número de habitantes se ha incrementado en León y empieza a recuperarse en Puebla. 
Por último, el programa ARI en León y el plan de regeneración urbana DUIS en Puebla, consisten en un modelo de rehabilitación integral e intervención, que contempla la sostenibilidad en todas sus dimensiones: social, ambiental y económica. Este modelo se integra a partir de la definición de los objetivos dentro de un diagnóstico previo del área. El Programa de Estrategias Integradas especifica cuáles son las instituciones públicas y privadas para cada una de estas acciones. Se estiman los costes y las fuentes de financiación, los compromisos y las subvenciones previstas para su desarrollo y seguimiento, justificando la viabilidad financiera de las operaciones propuestas.

Las Estrategias de Integración y Rehabilitación Urbana Sostenible son válidas para recuperar los centros históricos en otros países del mundo, adaptándolas a sus valores patrimoniales y culturales. Este tipo de intervenciones, que buscan orientar la toma de decisiones, es aplicable a los centros y barrios históricos independientemente de su propia especificidad. Es decir, esta metodología se erige como un modelo de explicación e indagación universal aplicable en este caso, de manera particular, al análisis comparativo de los centros históricos de León y de Puebla y a cualquier otra ciudad con similares problemas urbanísticos.

Fecha de recepción: 1 de agosto de 2014.

Fecha de aceptación: 15 de julio de 2015.

\section{BibLiogRAFÍA}

Acevedo Salomao, E. M. (2002): "Políticas de Revitalización para el Centro Histórico de la Ciudad de Morelia, México", en: Memorias III Seminario Internacional Patrimonio y Ciudad Contemporánea: políticas, prácticas y nuevos protagonistas. Brasil, CECRE-Facultad de Arquitectura de la Universidad Federal de Bahía.

Álvarez Mora, A. (dir.) (2013): Politicas urbanas aplicadas a los conjuntos históricos. Logros y fracasos. Hacia una propuesta de rehabilitación urbana como alternativa al modelo inmobiliario extensivo. Valladolid, Instituto Universitario de Urbanística de Valladolid.

Arvizu García, C. (1990): "Urbanismo Novohispano en el siglo xvI", en: Estudios sobre Urbanismo Iberoamericano, Siglos XVI al XVIII. Sevilla, Junta de Andalucía, Consejería de Cultura Asesoría V Centenario.

Audefroy, J. (2000): "Seis principios para la rehabilitación integral en los centros históricos". L'ordinaire latino-américan, 1/181, pp.23-28.

Blanc, B. et al. (ed.) (2003): La rehabilitación de la vivienda popular y del patrimonio. San José, Costa Rica, FLACSO.

Boira i Maiques, J. V. (1995): "La Rehabilitación urbana en los centros históricos Valencianos: el Caso de Valencia, Alicante y Alcoi”. Cuadernos de Geografia, 58, pp. 241- 
258.

Castells, M. y Borja J. (1997): Lo local y lo global: La gestión de las ciudades en la era de la información. Madrid, Grupo Santillana de Ediciones.

Chanfón Olmos, C. (1997): "Las ciudades Novohispanas", en: Historia de la Arquitectura y el Urbanismo Mexicanos. El Periodo Virreinal, vol. II. México, Universidad Autónoma de México, Fondo de Cultura Económica, pp. 199-227.

Collin Delavaud, A. (2008): “¿Aparición de una nueva cultura patrimonial en América Latina a través de los Centros Históricos en "Re-construcción?". Investigación y Desarrollo, 16/1, pp. 32-57.

Córdoba Montufar, M. (coord.) (2008): Lo urbano en su complejidad: una lectura desde América Latina. Flacso, Ecuador, Ministerio de Cultura.

Coulomb, R. (2009): Regeneración urbana y habitabilidad en los centros de la ciudad. Lo aprendido en la ciudad de México. San Salvador, Encuentro latinoamericano sobre Centros Históricos.

Coulomb, R. (coord.) (2010): México: centralidades históricas y proyectos de ciudad. México, Organización Latinoamericana y del Caribe de centros Históricos, Centralidades, vol. II, 475 págs.

García-Hípola, M. y Beltrán Rodríguez, M. (2011): "Hibridación y destrucción selectiva como estrategias propulsoras en centros históricos de Salamanca y Estocolmo". Ciudades, 14/1, pp.133-156.

García Centurión, J. A. (2011): Reutilización del centro histórico. Modelo teórico de intervención para la ciudad de Villahermosa. Tabasco, México, Universidad Nacional Autónoma de México.

García Espinosa, S. (2005): "Centros históricos ¿herencia del pasado o construcción del presente? agentes detonadores de un nuevo esquema de ciudad". Scripta Nova, 194, p. 39.

García Téllez R. M. (2006): Políticas de intervención en los centros históricos, caso Puebla (1982-2001). México, Fomento Editorial, BUAP.

González González, M. J. (2005): "El desarrollo económico sostenible de los centros históricos". Ería, 68, pp. 365-372.

Lalana Soto, J. L. (2011): "El paisaje urbano histórico: modas, paradigmas y olvidos". Ciudades, 14/1, pp. 15-38.

Levy, J. P. (1987): Centres villes en mutation. París, CNRS.

Manero, F. (2009): "De la protección selectiva a la recuperación de los espacios urbanos en situación crítica: las áreas de rehabilitación integrada en Castilla y León". Polígonos, 19, pp. 95-118.

Martínez Vicente, M. L. (coord.) (2014): La rehabilitación en el momento actual. Madrid, COAM.

Merton, R. K. (1995): "The Thomas Theorem and The Matthew Effect?" Social Forces, 74/2, pp. 79-424.

MIC (2013): "Políticas Urbanas en la rehabilitación de los centros históricos doce ejemplos latinoamericanos", en: II seminario internacional rii_uc primeros asenta- 
mientos españoles y portugueses en la américa central y meridional siglo XVI y XVII. Santa Fe, Argentina, Ministerio de Innovación y Cultura (MIC), pp. 54-68.

Milián Ávila, G. (2000): "Los nuevos enfoques para el ordenamiento de los centros históricos, el caso de Puebla, México". L'ordinaire Latino-Américain, 2/182, pp. 5-16.

Ramos Hidalgo, A. et al. (ed.) (2005): Recuperación de los Centros Históricos; Utopía, Negocio o Necesidad Social. Alicante, AGE, II Jornadas de Geografía Urbana.

Ramírez Rosete, N. L. (2014): Rehabilitación Urbana Sostenible, Estrategias de integración para los Barrios del Centro Histórico de la Ciudad de Puebla. México, Fomento Editorial.

Terán Bonilla, J. A. (2008): Antología del seminario de Arquitectura de Integración para Contextos Urbanos Históricos. Puebla (México), Colegio de Arquitectos de Puebla.

Terán Bonilla, J. A. (2010): Arquitectura y Urbanismo del Centro Histórico de la Ciudad de Puebla. México, Editorial Lunarena.

Tomé Fernández, S. (2007): "Los centros históricos de las ciudades españolas". Ería, 72, pp. 75-88.

Troitiño Vinuesa, M. A. (1992): Cascos antiguos y centros históricos: problemas, políticas y dinámicas urbanas. Madrid, MOPU.

Troitiño Vinuesa, M. A. (2003): "La Protección, recuperación y revitalización funcional de los centros históricos". Mediterráneo económico, 3, pp. 131-160.

Valverde Díaz de León, C. F. (2005): "Puebla: El más allá de la retícula, más acá en la pobreza". Ciudades, 9, pp.161-177.

\section{Páginas web}

Ayuntamiento de León. Plan de recuperación Áreas de Rehabilitación Integrada (ARI) y Sección de Estadística. www.aytoleon.es/es/ayuntamiento/areasmunicipales (Verificada: 31/09/2015).

INEGI, 2013. Censo de Población y Vivienda, Instituto Nacional de Estadística y Geografía. México. www.inegi.org.mx/ (Verificada: 31/09/2015).

Programa Parcial de Desarrollo Urbano y Conservación del Centro Histórico de la Ciudad de Puebla. Coordinador: Nicolás Esteban López Tamayo. http://www.oum puebla.com.mx/documents/disenofinalcapitulol.pdf (Verificada: 31/09/2015).

Plan para la Recuperación de la Zona de Monumentos en la Ciudad de Puebla. Coordinador: Francisco M. Vélez Pliego 1999-2001.

https://www.google.com.mx/webhp?hl=es-419\#hl=es-419\&q=programa-parcialde-desarrollo-urbano-del-municipio-de-puebla-y-bases-para-el-plan-de-manejopara-la-conservacion-del-centro-historico-de-la-ciudad-de-puebla

(Verificada: 31/09/2015).

http://www.quepuebla.com/index.php/noticias/locales/5501-proyecta-gali-resuci tar-al-centro-historico-crean-4-reservas-territoriales.pdf? type=raw

(Verificada: 31/09/2015). 


\section{RESUMEN}

En este trabajo se analizan los cambios que han sufrido los centros históricos de las ciudades de León (España) y Puebla (México) para realizar una comparación y poner de manifiesto que existen los mismos problemas en ambas ciudades. Los factores que determinan la problemática de los centros históricos, tales como la pérdida de vitalidad funcional y el deterioro físico y social, se evidencian en estos dos casos de estudio. Se plantea utilizar una Estrategia de Integración y Rehabilitación Urbana Sostenible, basada en características funcionales, formales, sociales y ambientales. Los resultados se expresan mediante la conservación del patrimonio histórico, los cambios en los usos del suelo y sus condiciones ambientales.

Palabras Clave: cascos históricos; rehabilitación urbana; intervención; sostenibilidad.

\section{Abstract}

In this study, changes that have taken place in the historical centre of León (Spain) and Puebla (Mexico) are analysed and compared to show that the same problems occur in the old quarter of both cities. Factors determinig these problems, such as loss of vitality and physical and social deterioration, are highlighted in the two case studies. The implementation of a Sustainable Urban Integration and Rehabilitation Strategy, based on functional, formal, social and environmental characteristics, is proposed. The results are expressed as the preservation of historical heritage, and changes in land use and its environmental conditions.

KEY WORDS: old cities; urban rehabilitation; intervention; sustainability.

\section{RÉSUMÉ}

La présente étude analyse les changements subis dans les centres historiques des villes de León (Espagne) et de Puebla (Mexique) afin de réaliser une comparaison et de mettre en évidence les problèmes très similaires partagés par les deux villes. Les facteurs déterminant la problématique des centres historiques, tels que la perte de la vitalité fonctionnelle ou la détérioration physique et sociale, sont mis en évidence dans les deux cas de notre étude. On instaure l'utilisation d'une Stratégie d'Intégration et Réhabilitation Urbaine Durable, fondée sur des caractéristiques fonctionnelles, formelles, sociales et environnementales. Les résultats s'expriment moyennant la préservation du patrimoine historique, les changements d'utilisation du sol et de ses conditions environnementales.

MoTS CLÉS: centres historiques; aménegement urbain; durabilité. 